\title{
Calidad sanitaria del agua potable consumida en la sede central de la Universidad Surcolombiana
}

\author{
Luz Edith Narváez Chamorro \\ Licenciada en Ciencias Naturales: Física, Química y Biología \\ luednacha_95@hotmail.com \\ Magda Lizeth Rivera Ardila \\ Licenciada en Ciencias Naturales: Física, Química y Biología \\ magda.liriar@gmail.com \\ Luisa Fernanda Tello Ruiz \\ Licenciada en Ciencias Naturales: Física, Química y Biología \\ luisa11474@hotmail.com \\ Luis Javier Narváez Zamora \\ Universidad Surcolombiana, Colombia \\ ljnz47@usco.edu.co
}

\section{Resumen}

El agua se ha convertido en la fuente principal de desarrollo y sostenimiento de los seres humanos, ha permitido el mejoramiento de la calidad de vida en el planeta; sin embargo actualmente no se le da la importancia que merece, cada vez está más limitada y presenta una problemática global debido al crecimiento poblacional, manejo inadecuado de las cuencas hidrográficas y a las actividades rutinarias que realizan los seres humanos que contribuyen a la degradación afectando su calidad y cantidad, logrando así la contaminación de los afluentes que proveen agua a las diferentes comunidades. Por consiguiente, el agua potable consumida en la sede central de la Universidad Surcolombiana de Neiva debe poseer una calidad sanitaria que garantice su consumo sin generar riesgo alguno para la salud humana.

En este sentido, se decidió evaluar la calidad sanitaria del agua potable consumida en la USCO sede central - Neiva, para verificar si esta cumple con las características físicas, químicas y bacteriológicas establecidas en el decreto número 1575 / 2007 y la resolución 2115/2007 del Ministerio de Protección Social, Ministerio de Salud, Ambiente, Vivienda y Desarrollo Territorial. Se realizó en un periodo de 4 meses, aplicando metodologías que consistieron de unas fases o etapas sucesivas (Bibliográfica, de muestreo, laboratorio, análisis de resultados y divulgación).

Palabras Clave: Agua potable, Calidad sanitaria, Análisis Fisicoquímico, Análisis Bacteriológico.

\section{Sanitary quality of drinking water consumed at the headquarters of the Universidad Surcolombiana}

\section{Abstract}

Water has become the main source of development and sustenance of human beings, it has allowed the improvement of the quality of life on the planet; However, it is not currently given the importance it deserves, is increasingly limited and presents a global problem due to the population growth, inadequate management of watersheds and routine activities carried out by humans who contribute to that degradation affecting their quality and quantity, thus achieving the contamination 
of the tributaries which provide water to the different communities. Consequently, drinking water consumed at the headquarters of Neiva's Surcolombian University must have a sanitary quality that guarantees its consumption without generating any risk to human health.

In this sense, it was decided to evaluate the sanitary quality of drinking water consumed in the USCO headquarters - Neiva, to verify if it complies with the physical, chemical and bacteriological characteristics established in decree number 1575/2007 and resolution 2115/2007 Ministry of Social Protection, Ministry of Health, Environment, Housing and Territorial Development. It was carried out in a period of 4 months, applying methodologies that consisted of successive phases or stages (Bibliographic, sampling, laboratory, analysis of results and dissemination).

Keywords: Drinking water, Health quality, Physicochemical analysis, Bacteriological analysis.

\section{Introducción}

El agua, es el recurso de mayor importancia del cual depende nuestra vida y nuestro medio ambiente, algunos organismos viven en ella y todos nos mantenemos gracias a ella. El agua constituye del 60 al $75 \%$ del peso de un organismo, presenta propiedades físicas y químicas las cuales la diferencian de la mayoría de demás líquidos y ha permitido que todos los seres vivos hayan sido viables, sobrevivan y evolucionen constantemente en el planeta tierra. A lo largo de la historia, el agua se ha convertido en la fuente principal de desarrollo y sostenimiento de los seres humanos, pues ha permitido el mejoramiento de la calidad de vida; sin embargo actualmente no se le da la importancia que merece, debido a que es uno de los recursos más desperdiciados, y cada vez es más difícil encontrarlo en óptimas condiciones de consumo para satisfacer nuestras necesidades.

Teniendo como referencia la actividad antrópica donde se destacan aspectos tales como el manejo agrícola, pecuario, la explotación petrolera y el alto grado de contaminación al que ha sido sometido el Rio Las Ceibas, principal fuente de abastecimiento del agua para los habitantes de la ciudad de Neiva, incluyendo la población universitaria Surcolombiana; se realizó un estudio de la calidad sanitaria del agua potable consumida en la sede central de la USCO, para verificar si cumple con los parámetros físicos, químicos y bacteriológicos establecidos en el Decreto número 1575 / 2007 y la Resolución 2115/2007 del Ministerio de Protección Social,
Ministerio de Ambiente, Vivienda y Desarrollo Territorial; los cuales determinan el sistema para la protección y control de la calidad del agua, con el fin de monitorear, prevenir y controlar los riesgos para la salud humana causados por su consumo, exceptuando el agua envasada. Aplica a todas las personas prestadoras que suministren o distribuyan agua para consumo humano, ya sea cruda o tratada, en todo el territorio nacional, independientemente del uso que de ella se haga para otras actividades económicas, a las direcciones territoriales de salud, autoridades ambientales y sanitarias y a los usuarios.

El presente artículo muestra los resultados obtenidos sobre la calidad sanitaria incluyendo las características fisicoquímicas básicas, la cuantificación de Coliformes, metales pesados y pesticidas en el agua consumida por la comunidad en general de la Universidad Surcolombiana en su sede central.

\section{Desarrollo}

Durante los últimos años se han llevado a cabo diferentes investigaciones sobre la calidad sanitaria del agua y demás productos de consumo humano, las cuales dan relevancia y demuestran la importancia y valor de este tipo de investigación, dentro de los cuales se encuentran:

“El análisis microbiológico de alimentos preparados en la vía pública en los alrededores de la Universidad Surcolombiana mediante el estudio de Coliformes", llevado a cabo por 
María Alicia Pérez Rubiano en el año 2015, el cual tuvo como objetivo determinar el tipo de Coliformes que se encuentran en los alimentos preparados en el restaurante, las cafeterías y la vía pública de los alrededores de la Universidad Surcolombiana en la ciudad de Neiva, hallando como resultados la detección e identificación de E. Coli $\mathrm{H}_{7}$ y Shigella spp.

La calidad sanitaria de la leche pasteurizada y consumida en Neiva del año 1995. "Cuidado con el consumo de leche mal pasteurizada", estudio realizado por Luis Javier Narváez y Martha Ramírez Plazas, el cual permitió concluir que la leche pasteurizada producida en Neiva es de mala calidad sanitaria debido a las faltas en el proceso de pasteurizado,empacadoorefrigeradoy suconsumo puede presentar riesgos en la salud humana. Se halló que el $90 \%$ de las muestras sobrepasa los límites permisibles de microorganismos mesófilos, el $58 \%$ de las leches pasteurizadas presentan un elevado número de Coliformes totales y el 35\% de las muestras contienen más de 1.100 Coliformes por litro. El análisis permitió la identificación de Staphylococcus Aureus en el $40 \%$ y en un $90 \%$ de Echerichia Coli.

El estudio titulado "Caracterización fisicoquímica y bacteriológica preliminar del agua de consumo humano de la vereda 'El Dindal' zona rural del municipio de Aipe, Huila- Colombia" fue adelantado por Rojas y Gaona en el año 2012, y su objetivo fue analizar en términos fisicoquímicos y bacteriológicos el agua de consumo de dicha vereda como una estrategia para caracterizar su calidad sanitaria; en donde dentro de los principales hallazgos, se encuentra que el $\mathrm{pH}$, no cumple con lo establecido en el decreto 475/1998 del Ministerio de Salud Pública, lo que determinó la presencia de alcalinidad por carbonatos y bicarbonatos, presencia de contenidos de bicarbonatos, lo que hace que el agua de consumo presente un aspecto jabonoso y un sabor amargo, presencia de concentraciones de Nitrato que exceden lo establecido en el decreto, que tienen su origen debido al uso de fertilizantes y por último la presencia de coliformes fecales y totales, que hacen referencia a la presencia de Escherichia Coli o Enterobacter Aerogenes.
“¿Es potable el agua que se consume en Neiva?", título de la investigación realizada por Barrios en el año 2000, cuyo objetivo fue evaluar la eficiencia de la planta de tratamiento en el proceso de potabilización del agua por parte de las empresas públicas de Neiva, obteniendo como resultado que se cumple con los parámetros físicos, químicos y bacteriológicos exigidos en el decreto 475/1998 haciéndose apta para el consumo humano.

“El análisis microbiológico de coliformes y determinación de Salmonella en la carne de pollo expendida en la central minorista Mercaneiva", realizado por Gómez en el año 2001, con el objetivo de determinar la prevalencia de coliformes y la bacteria del genero Salmonella en la carne de pollo distribuida en Mercaneiva, siendo esta de buena calidad.

“Evaluación de la calidad microbiológica del agua envasada en bolsas producida en Sincelejo-Colombia", llevada a cabo por Vidal y sus colaboradores en el año 2008, con el objetivo de evaluar la calidad microbiológica y físicoquímica del agua envasada en bolsas producidas en la ciudad de Sincelejo-Colombia con destino al consumo humano. Entre los hallazgos se encuentra, que gran parte del agua envasada en bolsas de la ciudad de Sincelejo genera un riesgo a la salud de los consumidores, debido a la presencia de microorganismos patógenos, por inadecuados procesos de producción y a la intermitencia del suministro del agua utilizada como materia prima.

Por último, encontramos la investigación titulada "Determinación de la calidad de agua mediante indicadores biológicos y fisicoquímicos en la estación piscícola de la Universidad de Caldas, municipio de Palestina, Colombia"; realizada por Hahn-vonHessberg y sus colaboradores en el año 2009, cuyo objetivo fue determinar la calidad del agua mediante macro-invertebrados acuáticos y parámetros fisicoquímicos en la Estación Piscícola, Granja Montelindo, ubicada en la vereda Santagueda, en donde se obtuvo como resultado que el agua que circula en la estación piscícola es de clase tres o medianamente contaminada, no se observó 
deterioro de la calidad de agua. Se encontraron hongos pertenecientes a los grupos Oomycetos, Phycomycetos y Zygomicetos.

Según la Resolución 2115 de 2007 y el Decreto 1275 de 2007, el agua potable es aquella que cumple en su totalidad con las características físicas, químicas y microbiológicas que están establecidas en ambos reglamentos. El agua debe presentar un color traslucido con un valor de 15 UPC (Unidades de Platino Cobalto), un olor y sabor aceptable, una turbiedad máxima aceptable de 2 UNT (Unidades Nefelometricas de Turbiedad), una conductividad máxima de 1000 microsiemens/cm, dureza de $300 \mathrm{mg} / \mathrm{l}$, temperatura $\leq 30^{\circ} \mathrm{C}$, $\mathrm{pH}$ entre 6,5 y 9 , un valor máximo aceptable de concentraciones de plaguicidas de $0,1 \mathrm{mg} / \mathrm{l}$.

El rango permisibles de algunas sustancias químicas presentes en el agua son: Cobre $(1,0 \mathrm{mg} / \mathrm{l})$, Cloruros (250 mg/l), Hierro (0,3 mg/l), Mercurio $(0,001 \mathrm{mg} / \mathrm{l})$, Nitritos $(0,1 \mathrm{mg} / \mathrm{l})$, Nitratos $(10 \mathrm{mg} / \mathrm{l})$, Sulfatos $(250 \mathrm{mg} / \mathrm{l})$ y Plomo $(0,01)$, cantidades que no deben exceder los valores máximos descritos en este decreto porque generarían un efecto negativo y nocivo para la salud de sus consumidores.

Las características microbiológicas del agua potable, deben estar comprendidas dentro de los siguientes valores máximos aceptables, los cuales se establecen teniendo en cuenta los límites de confianza del 95\% y el tipo de técnica utilizada. Para la determinación de coliformes totales y Escherichia Coli, microorganismos analizados durante la investigación, por la técnica de filtración por membrana se debe tener un valor de $0 \mathrm{UFC/}$ $\mathrm{Cm}^{3}$, por la técnica enzima sustratro se deben hallar $<1$ microorganismo en $100 \mathrm{~cm}^{3}$, por sustrato definido 0 microorganismos en $100 \mathrm{~cm}^{3}$ y por presencia - ausencia, ausencia total en $100 \mathrm{~cm}^{3}$.

\section{Materiales y Métodos}

El estudio se realizó mediante un análisis fisicoquímico, bacteriológico y de pesticidas durante un periodo de 4 meses, aplicando metodologías que constan de 5 etapas sucesivas (Bibliográfico, de muestreo, laboratorio, análisis de resultados y divulgación).

La etapa bibliográfica, consistió en la recolección de información de todo lo referente al tema objeto de la investigación. La etapa de muestreo comprendió 2 fases, según los datos obtenidos de la Universidad Surcolombiana, la población total de la sede central es de 8965 personas, por lo tanto conforme al artículo 21 de la resolución $2115^{1}$, se estableció el número de muestras de control de calidad física y química del agua para consumo humano, donde se recolectaron 8 muestras en diferentes lugares objeto de investigación. (Ver tabla No. 1).

Tabla 1. Características de los sitios de recolección de las muestras, primer y segundo muestreo.

\begin{tabular}{|c|c|c|c|}
\hline \multirow{2}{*}{$\begin{array}{l}\text { Número } \\
\text { de } \\
\text { Muestra }\end{array}$} & \multirow[t]{2}{*}{ Sitio de Toma de Muestra } & \multicolumn{2}{|c|}{ Coordenadas } \\
\hline & & Latitud & Longitud \\
\hline 1 & $\begin{array}{l}\text { Lavamanos consultorio edificio } \\
\text { de bienestar }\end{array}$ & $2^{\circ} 56^{\prime} 32,1^{\prime \prime} \mathrm{N}$ & $75^{\circ} 17^{\prime} 52,84^{\prime \prime} \mathrm{W}$ \\
\hline 2 & Restaurante universitario & $2^{\circ} 56^{\prime} 30,51^{\prime \prime} \mathrm{N}$ & $75^{\circ} 17^{\prime} 59,76^{\prime \prime} \mathrm{W}$ \\
\hline 3 & Lavaplatos Cafetería USCO & $2^{\circ} 56^{\prime} 30,12^{\prime \prime} \mathrm{N}$ & $75^{\circ} 17^{\prime} 57,76^{\prime \prime} \mathrm{W}$ \\
\hline 4 & $\begin{array}{l}\text { Baños de mujeres facultad de } \\
\text { educación }\end{array}$ & $2^{\circ} 56^{\prime} 30,36^{\prime \prime} \mathrm{N}$ & $75^{\circ} 17^{\prime} 55,05^{\prime \prime} \mathrm{W}$ \\
\hline 5 & Baño bloque de artes & $2^{\circ} 56^{\prime} 32,52^{\prime \prime} \mathrm{N}$ & $75^{\circ} 17^{\prime} 53,41^{\prime \prime} \mathrm{W}$ \\
\hline 6 & $\begin{array}{l}\text { Baño de hombres de la facultad } \\
\text { de educación }\end{array}$ & $2^{\circ} 56^{\prime} 31,32^{\prime \prime} \mathrm{N}$ & $75^{\circ} 17^{\prime} 56,52^{\prime \prime} \mathrm{W}$ \\
\hline 7 & $\begin{array}{l}\text { Baño de mujeres edificio de } \\
\text { economía }\end{array}$ & $2^{\circ} 56^{\prime} 35,23^{\prime \prime} \mathrm{N}$ & $75^{\circ} 18^{\prime} 3,25^{\prime \prime} \mathrm{W}$ \\
\hline 8 & $\begin{array}{l}\text { Baño de mujeres edificio de } \\
\text { ingeniería. }\end{array}$ & $2^{\circ} 56^{\prime} 40,28^{\prime \prime} \mathrm{N}$ & $75^{\circ} 17^{\prime} 59,76^{\prime \prime} \mathrm{W}$ \\
\hline
\end{tabular}

1 Resolución 2115/22 de junio de 2007, por medio del cual se señalan características, instrumentos básicos y frecuencias del sistema de control y vigilancia para la calidad del agua para consumo humano. 
En la etapa de laboratorio se realizó el análisis fisicoquímico, implementando técnicas como: espectrofotometría UV-Vis, cromatografía de gases, colorimetría con Kits AquaMerck (Cuantificación de dureza, $\mathrm{pH}$, color, nitritos y sulfatos). Un análisis bacteriológico para Coliformes totales, efectuando filtración por membrana. Un análisis de pesticidas cuya técnica a utilizar fue la cromatografía de gases. Una etapa de análisis de resultados, donde se requirió herramientas estadísticas para determinar el estado de cada uno de los parámetros aplicados y por último la etapa de divulgación, con el fin de informar a la comunidad el estado actual en el que se encuentra el agua que llega a las instalaciones de la Universidad Surcolombiana y en caso de hallazgos relevantes ejecutar medidas preventivas.

\section{Resultados y Discusión}

El agua en estudio presentó valores que se encuentran descritos en las tablas Nos. 2 y 3, para luego ser analizados de acuerdo con la normatividad colombiana vigente Resolución 2115 de 2007 y Decreto 1575 de 2007:

Tabla 2. Resultados de las pruebas realizadas a las muestras recolectadas el 13 de Octubre.

\begin{tabular}{|c|c|c|c|c|c|c|c|c|c|}
\hline \multirow{2}{*}{\multicolumn{2}{|c|}{ Pruebas }} & \multicolumn{8}{|c|}{ Muestreo 1} \\
\hline & & 1 & 2 & 3 & 4 & 5 & 6 & 7 & 8 \\
\hline \multicolumn{2}{|c|}{$\begin{array}{l}\text { Bacteriológica } \\
\text { (Coliformes Totales UFC) }\end{array}$} & 0 & 1 & 1 & 0 & 0 & 1 & 0 & 0 \\
\hline \multirow{2}{*}{\multicolumn{2}{|c|}{$\begin{array}{l}\text { Pesticidas } \\
\text { Metales Pesados }(\mathrm{Pb}, \mathrm{Hg} \text {, } \\
\mathrm{Cu})\end{array}$}} & -- & -- & -- & -- & -- & -- & -- & -- \\
\hline & & -- & -- & -- & -- & -- & -- & -- & -- \\
\hline \multirow{8}{*}{$\begin{array}{l}\text { Análisis } \\
\text { Fisicoquímicos }\end{array}$} & $\begin{array}{l}\text { Color Real } \\
\text { (UPC) }\end{array}$ & 0 & 0 & 0 & 0 & 0 & 0 & 0 & 0 \\
\hline & $\begin{array}{l}\text { Olor y } \\
\text { Sabor }\end{array}$ & A & A & $\mathrm{A}$ & A & $\mathrm{A}$ & $\mathrm{A}$ & $\mathrm{A}$ & $\mathrm{A}$ \\
\hline & $\begin{array}{l}\text { Dureza } \\
\left({ }^{\circ} \mathrm{f}\right)\end{array}$ & 7,12 & 7,12 & 5,34 & 7,12 & 5,34 & 7,12 & 5,34 & 5,34 \\
\hline & \multicolumn{2}{|c|}{$\begin{array}{l}\text { Temperatura } \\
24,9 \\
{ }^{\circ} \mathrm{C}\end{array}$} & 27,5 & 26,8 & 26 & 26,6 & 26 & 26,3 & 25,8 \\
\hline & $\mathrm{pH}$ & 7,63 & 7,66 & 7,67 & 7,91 & 7,49 & 7,64 & 7,52 & 7,74 \\
\hline & $\begin{array}{l}\text { Cloruros } \\
(\mathrm{mg} / \mathrm{l})\end{array}$ & 5 & 5 & 5 & 5 & 5 & 5 & 5 & 5 \\
\hline & $\begin{array}{l}\text { Nitritos } \\
(\mathrm{mg} / \mathrm{l})\end{array}$ & 0 & 0 & 0 & 0 & 0 & 0 & 0 & 0 \\
\hline & $\begin{array}{l}\text { Sulfatos } \\
\text { (ppm) }\end{array}$ & 80 & 110 & 80 & 80 & 110 & 80 & 80 & 110 \\
\hline
\end{tabular}


Tabla 3. Resultados de las pruebas realizadas a las muestras recolectadas el 28 de noviembre.

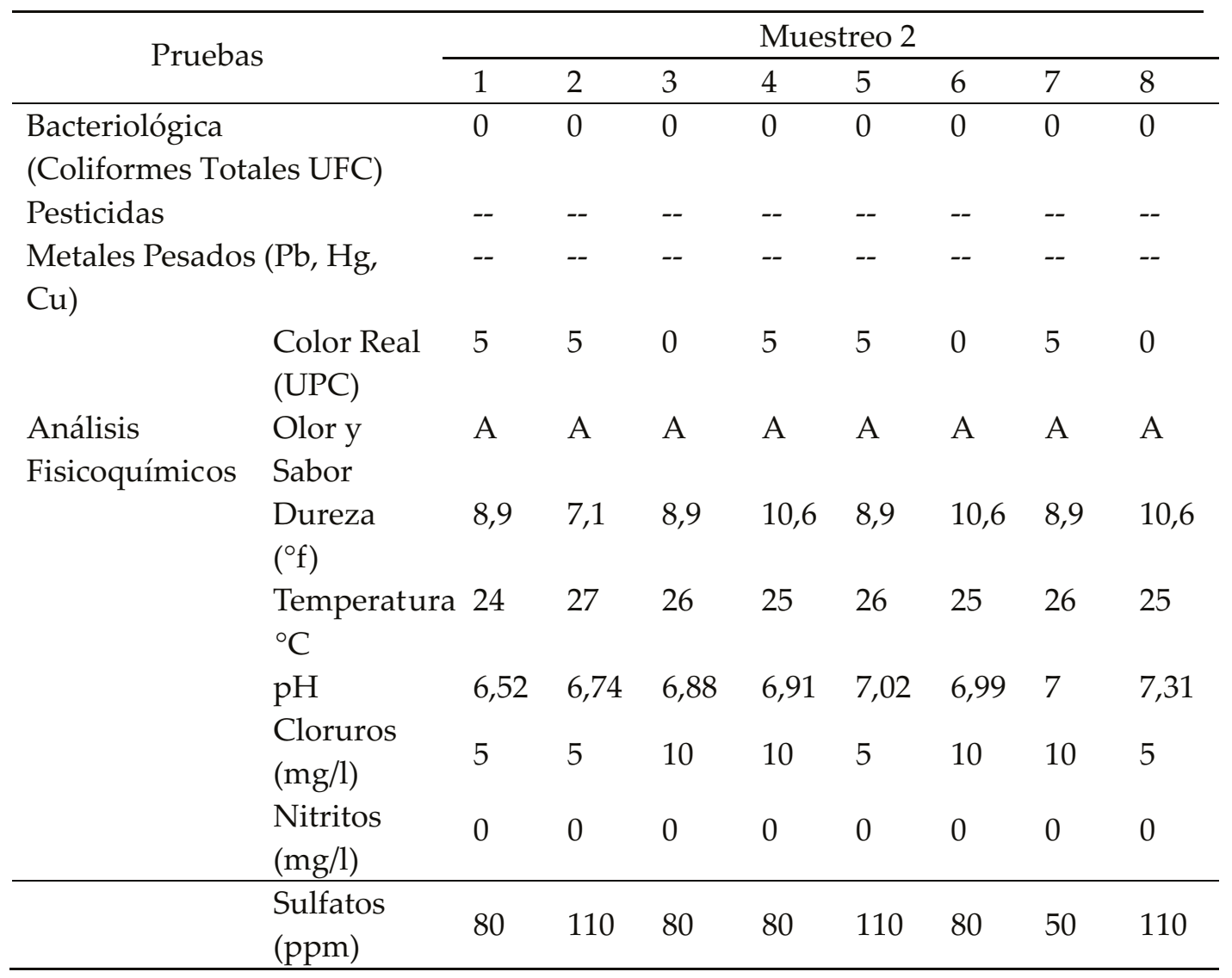

Los valores obtenidos en los dos muestreos indican en el análisis fisicoquímico que la dureza del agua es blanda, ya que no excede los $15^{\circ} \mathrm{f}$ (Grado francés, $\mathrm{mg} \mathrm{CaCO}_{3}$ por litro) y de acuerdo a la Resolución, el rango máximo es $30^{\circ} \mathrm{f}$. El valor de dureza se puede modificar por presencia de cloruros y sulfatos que hacen del agua más blanda.

En el caso de la temperatura, la variación de un muestreo a otro, se asocia con factores ambientales. El primer muestreo se realizó en octubre, mes de poca precipitación y elevadas temperaturas, a diferencia del segundo muestreo realizado en noviembre, mes de altas lluvias según el IDEAM dentro de su informe mensual.

Los valores de $\mathrm{pH}$ se asocian a la temperatura y condición climática de la recolección de las muestras. Esta propiedad química cumple con el rango permisible de 6,5 a 9 establecido en la (Resolución 2115 de 2007).
El test de cloruros, permitió determinar concentraciones de 5 y $10 \mathrm{mg} / \mathrm{l}$, valores que permiten comprobar que el agua, con respecto a la concentración de cloruros, es apta para el consumo. Los cambios de concentración se deben a la diferencia de tiempo en que se realizó el análisis.

La cuantificación de nitritos, permite determinar que el agua cumple con el rango permisible de $0,1 \mathrm{mg} / \mathrm{l}$. Este es un resultado adecuado con respecto a la normatividad, debido a que reduce los niveles de metahemoglobinemia y niveles de nocividad en la salud humana.

Respecto a los resultados sobre sulfatos los resultados no cambian en grandes escalas, la cantidad de sulfatos $\mathrm{SO}_{4}{ }^{-2}$ permisible en el agua potable es de $250 \mathrm{mg} / \mathrm{l}$. La cantidad de sulfatos en el agua analizada es mínima, no sobrepasa el valor máximo permitido y por ende no ejerce efecto negativo en la salud del consumidor. 
Los metales pesados analizados Cobre $(\mathrm{Cu})$, Mercurio $(\mathrm{Hg})$ y Plomo $(\mathrm{Pb})$ no se encuentran presentes en el agua potable de la Universidad. Por otra parte, se analizaron 3 tipos de pesticidas Trifloxystrobin, Propineb y Difenoconazol, usados en cultivos de pancoger de la cuenca del Rio Las Ceibas los cuales no presentan valores de concentraciones riesgosas para la salud de las personas consumidoras de este recurso hídrico.

En cuanto al análisis bacteriológico, la prueba para determinar presencia de Coliformes Totales, en el primer muestreo arroja un valor positivo para 3 de las 8 muestras analizadas. Estas muestras arrojaron un valor de 1 UFC cada una lo cual se considera alarmante por las acciones adversas de estos agentes bacteriológicos en la salud humana. De acuerdo con la norma, el valor de Coliformes Totales debe ser 0 UFC. Las posibles explicaciones a este resultado son: un aumento en la población usuaria del servicio, un mayor uso de aguas residuales, también la transmisión por alimentos, manos, utensilios o ropa contaminados, haciendo de la higiene sea deficiente. Para el caso del segundo muestreo, no hay presencia de Coliformes totales en las muestras analizadas.

\section{Conclusiones}

El agua potable consumida en la sede central de la Universidad Surcolombiana, cumple con todos los rangos permisibles con respecto a las características fisicoquímicas establecidas en la Resolución 2115 de 2007 y el Decreto 1575 de 2007. El agua posee un color aparente y real adecuado, un olor y sabor aceptable, una dureza blanda, una temperatura entre 24 y $27,5^{\circ} \mathrm{C}$ siendo apta para el consumo, un $\mathrm{pH}$ que varía entre 6,52 y 7, 91, el cual revela la ausencia de agentes contaminantes. Existe ausencia total de una de las sustancias que tienen efecto adverso en la salud humana, como lo son los nitritos; con respecto a los cloruros y sulfatos se presentan en una concentración mínima pero se encuentra dentro de la cantidad establecida en la normatividad, sin causar ningún daño a la población usuario de este recurso.
Uno de los aspectos más relevantes y de mayor atención es la presencia de Coliformes Totales en algunos puntos de distribución del recurso hídrico, en vista de que el valor obtenido fue de $1 \mathrm{UFC} / 100 \mathrm{~cm}^{3}$ y de acuerdo con la Resolución 2115 de 2007 dentro de las características microbiológicas que debe presentar el agua potable, no puede presentarse ningún valor de Coliformes Totales en la misma. Por ende, es necesario hacer una revisión continua de las redes de distribución del agua y de los puntos específicos donde el resultado fue positivo, con el fin de garantizar a la comunidad usuario un recurso apto para su utilización.

Por otro lado se cumple satisfactoriamente las características químicas que tienen reconocido efecto adverso en la salud humana que se plantea en el reglamento establecido por la Resolución 2115/2007, respecto a la cantidad de metales analizados como Cobre, Mercurio y Plomo obtenidos en los dos muestreos realizados mediante la técnica de ultravioleta que ha realizado una medición de concentraciones con mucha exactitud para el desarrollo del trabajo investigativo de la calidad del agua potable consumida en la universidad Surcolombiana sede central, siendo esta de un valor para los tres metales de 0,000 ppm, lo cual no causa alguna problemática en la salud de la población que hace uso de este importante líquido.

Ahora bien, respecto a las trazas de pesticidas hallados en las muestras nos confirma que no hay valores que indiquen concentración riesgosa, de tal modo la calidad del agua que llega a las instalaciones de la USCO es apta para el consumo humano, pues la presencia de compuestos que usualmente se utilizan para la erradicación y control de plagas en los campos y zonas urbanas aledañas a la cuenca del Rio Las Ceibas es muy pequeña, la cual no provoca graves daños en el organismo de la población que actualmente hace uso de este servicio.

\section{Referencias bibliográficas}

Barrenechea, A. (2006). Aspectos Fisicoquímicos de la Calidad del agua. Capítulo 1. Obtenido de http://www.bvsde.paho.org/bvsatr/ 
fulltext/tratamiento/manualI/tomoI/uno. pdf

Barrios, L. F. (2000). ¿Es Potable el Agua que se Consume en Neiva?. Tesis de pregrado, Universidad Surcolombiana, Huila, Neiva.

Gomez, L. (2001). Análisis Microbiológico de Coliformes y Determinación de Salmonella en la Carne de Pollo Expendida en la Central Minorista "Mercaneiva. Tesis de Pregrado, Universidad Surcolombiana, Huila, Neiva.

Hahn-vonHessberg, C. e. (2009). Determinación de la Calidad de Agua Mediante Indicadores Biológicos y Fisicoquímicos, en la Estación Piscícola, Universidad de Caldas, Municipio de Palestina, Colombia. Scielo.

Massol - Deyal, A. (2002). Manual de Laboratorios: Ecología de Microorganismos. Universidad de Puerto Rico. Obtenido de http://www. uprm.edu/biology/profs/massol/manual/ p1-intro.pdf

Ministerio de la Protección Social, M. d. (22 de Junio de 2007). Ministerio de Ambiente. Recuperado el 14 de Octubre de 2016, de http://www.minambiente.gov.co/images/
GestionIntegraldelRecursoHidrico/ pdf/Legislaci\%C3\%B3n_del_agua/ Resoluci\%C3\%B3n_2115.pdf

Narváez Zamora, L. J., \& Ramírez Plazas, M. (1995). Calidad Sanitaria e la Leche Pasteurizada y Consumida en Neiva. "Cuidado con el consumo de la Leche Mal Pasteurizada". Entorno, 53-58.

Perez, A. (2015). Analisis Microbiologico de Alimentos Preparados en la Via Publica en los Alrededores de la Universidad Surcolombiana Mediante el Estudio de Coliformes. Tesis de Pregrado para optar el titulo de Licenciado en Ciencias Naturales: Fisica, Quimica y Biologia., Universidad Surcolombiana, Huila, Neiva.

Rojas, L., \& Gaona, M. (2012). Caracterización Fisicoquimica y Bacteriologica Preliminar del Agua de Consumo Humano de la Vereda "El Dindal" del Municipio de Aipe. Tesis de Pregrado, Universidad Surcolombiana, Huila, Neiva.

Vidal, J. (2008). Evaluación de la Calidad Microbiológica del Agua Envasada en Bolsas Producida en Sincelejo - Colombia. Scielo. 